\title{
A rare urological presentation of appendicitis
}

\author{
Nick Simson, Thomas Stonier, Alberto Coscione, Ahmed Qteishat
}

Department of Urology, Princess Alexandra Hospital NHS Trust, Harlow, UK

\section{Correspondence to Dr Nick Simson,} njsimson@gmail.com

Accepted 25 July 2017
To cite: Simson N, Stonier T, Coscione A, et al. BMJ Case Rep Published Online First: [please include Day Month Year]. doi:10.1136/bcr-2017220546

\section{SUMMARY}

A 17-year-old boy with no medical comorbidities, but a significant family history of malignancy, presented to Accident and Emergency following 3 days of increasing rectal pain, symptoms of bladder outflow obstruction (poor flow, intermittent stream and hesitancy) and dysuria. Notably he had no abdominal pain. Digital rectal examination revealed a tender, enlarged prostate. Inflammatory markers were significantly raised (white cell count 17.7, C reactive protein 191). He was diagnosed clinically as prostatitis and commenced on intravenous antibiotics. Despite this his pain and inflammatory markers deteriorated, necessitating a $\mathrm{CT}$ of his abdomen and pelvis. This demonstrated multiloculated large thick-walled abscesses in the pelvis closely related to the rectum, prostate and seminal vesicles with some bowel wall thickening. Laparoscopy demonstrated a large colonic mass adherent to surrounding structures. The procedure was converted to laparotomy to enable resection of the mass via a limited right haemicolectomy. He recovered well and was discharged. Histopathological analysis of the specimen revealed appendicitis.

\section{BACKGROUND}

This case describes an extremely unusual presentation of a common surgical emergency that initially led to misdiagnosis. Despite the notoriously variable presentation of appendicitis, it is uncommon to have no abdominal pain whatsoever, and even more unusual to present with symptoms of prostatitis. There is indeed only one previous case described in the literature. ${ }^{1}$ Due to the presenting symptoms, his initial assessment and investigation were carried out by the Urology team. This case serves as a valuable reminder of the variable presentation of appendicitis-a diagnosis that should not be limited to the general surgeons alone.

\section{CASE PRESENTATION}

A 17-year-old boy without any medical history presented to our emergency department on a Saturday afternoon, complaining of 3 days of increasing rectal pain, poor urinary flow, hesitancy, terminal dribbling and dysuria. He had no abdominal pain whatsoever. He had felt feverish over the past 2 days and had demonstrated rigours while in the department.

He did not report any change in bowel habits, nausea or weight loss. Nor did he have any obvious risk factors for prostatitis; an unremarkable sexual history, no previous urinary tract infections, no urological procedures and no history of pelvic trauma.

He had a significant family history of juvenile ovarian and bowel cancer.

On examination his abdomen was entirely soft and non-tender throughout, he was tachycardic at 105 beats $/ \mathrm{min}$, with a low grade fever of $37.5^{\circ} \mathrm{C}$. A digital rectal examination revealed a tender, enlarged prostate.

He was diagnosed with prostatitis after clinical history and examination, and commenced intravenous antibiotic therapy, intravenous fluid resuscitation and analgesic treatment.

His case was discussed with the radiology consultant, who concluded that irradiation with a CT abdomen was inappropriate given his age and likely diagnosis, and that better imaging of the prostate would be achieved via transrectal ultrasound or MRI of the pelvis.

Acutely over the weekend, a transabdominal ultrasound was organised.

\section{INVESTIGATIONS}

Initial blood tests revealed a marked rise in inflammatory markers (white cell count 17.7, C reactive protein (CRP) 191). Urine dipstick was negative for leucocytes, nitrites and protein, with only a trace of blood.

A transabdominal ultrasound reported findings consistent with prostatitis, despite acknowledgement that this was not the ideal form of imaging the prostate and surrounding structures (figure 1).

Despite initial resuscitation and antibiotic therapy, the patient deteriorated, becoming febrile, tachycardic and complaining of increased pain. His inflammatory markers worsened (CRP 300).

He underwent an urgent $\mathrm{CT}$ of his abdomen and pelvis with contrast overnight, which demonstrated a multiloculated, large, thick-walled abscess in the

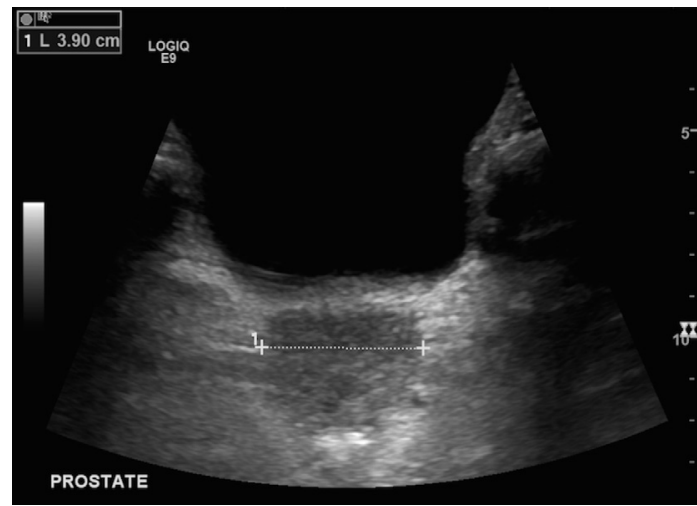

Figure 1 Transabdominal ultrasound. 


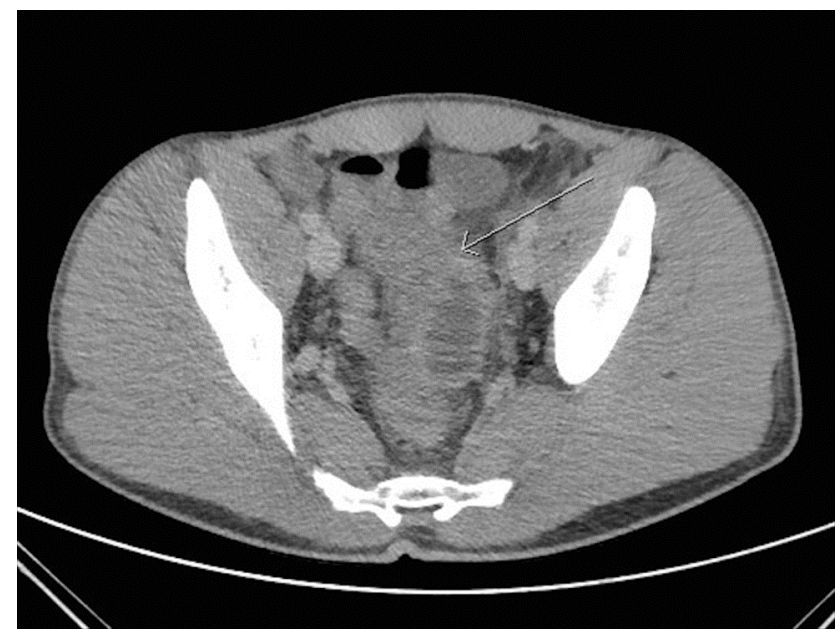

Figure 2 CT abdomen and pelvis demonstrating multi -loculated pelvic collection.

pelvis (measuring $8.5 \times 8.8 \times 3.2 \mathrm{~cm}$ ), closely related to the rectum, prostate and seminal vesicles with some bowel wall thickening in the sigmoid colon (figures 2 and 3).

\section{DIFFERENTIAL DIAGNOSIS}

Initial history and examination was consistent with a diagnosis of prostatitis, though clearly this is unusual in a young man with no risk factors for prostatitis.

Following his deterioration and CT findings of a pelvic abscess, the differential diagnosis shifted towards an appendicular, prostatic or colonic abscess. Given his family history of juvenile cancer, there remained a suspicion of colorectal malignancy as a differential, though clearly this was remote given the acute history and rapid deterioration.

\section{TREATMENT}

The patient underwent an emergency laparoscopy, which revealed a large colonic mass forming the wall of the pelvic abscess. This large mass was found to be adherent to the caecum, sigmoid, rectum and posterior wall of bladder. The appendix was not visualised separate to the mass. With difficult dissection laparoscopically, the operation was converted via a lower midline incision.

Purulent fluid was drained from the abscess, and blunt dissection was able to separate the remaining adherent mass from the sigmoid, bladder and rectum, however the caecum was unable to be separated from the mass.

A limited right haemicolectomy of the caecum and associated mass was performed, with a primary ileocolic anastomosis and thorough washout of the pelvis. A defunctioning ileostomy was not performed, and no intra-abdominal drains placed.

The specimen was sent for histopathological analysis.

\section{OUTCOME AND FOLLOW-UP}

He recovered well and was discharged on the second postoperative day after mobilising well, tolerating a normal diet and opening his bowels. He awaited his pathology results.

Histopathological analysis of the suspicious mass demonstrated a haemorrhagic, inflamed appendix with marked fibrinopurulent serositis (figure 4).

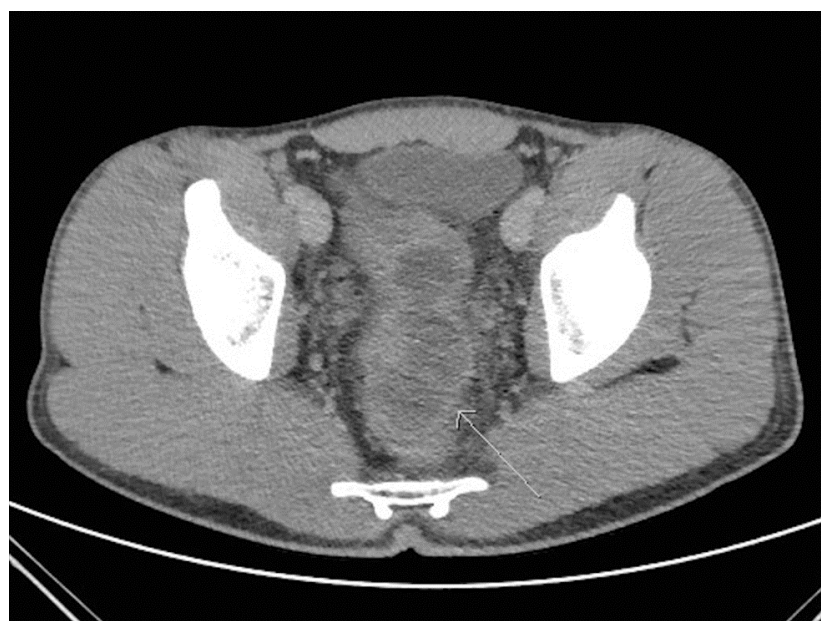

Figure 3 CT abdomen and pelvis.

\section{DISCUSSION}

The anatomic variation of the appendix is well known. ${ }^{2}$ As a result, acute appendicitis is notorious for its variable signs and symptoms, including in this rare case, those of prostatic obstruction and urinary tract infection. While the symptoms, initial radiological findings and family history of intra-abdominal neoplasm may have suggested a more unusual or sinister aetiology, it is important to rule out common pathology initially.

However, this is a complicated case, with only one similar case discussed in the literature in $1988 .^{1}$ In this paper, the authors describe three cases of confirmed appendicitis that presented with symptoms suggestive of urological disease: gross haematuria, acute prostatitis and acute pyelonephritis. While appendicitis causing gross haematuria is previously reported, the authors remark that appendicitis presenting with symptoms of prostatitis has not been described in the literature.

They describe a case of a 39-year-old man with abdominal pain, dysuria and intense pain on termination of urination. $\mathrm{He}$ had a tender enlarged, oedematous prostate on examination but deteriorated despite broad-spectrum antibiotics after initial diagnosis of prostatitis. Exploratory laparotomy revealed a perforated pelvic appendix with a retrovesical abscess. The patient recovered well after drainage of the abscess and appendicectomy.

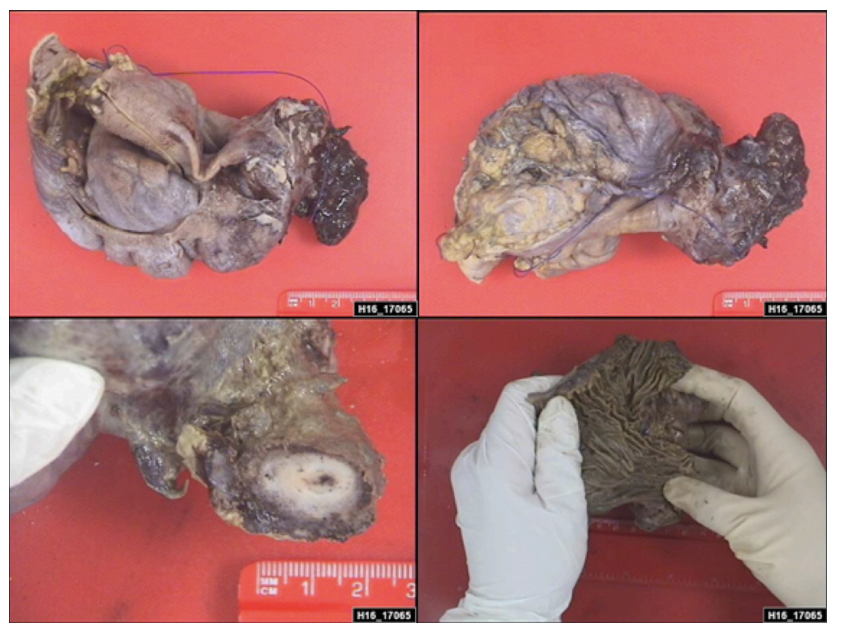

Figure 4 Histopathological specimen. 
This case is similar in both symptomology and management, though a key differentiating feature is the lack of any abdominal pain in our case.

Another study describing the urological presentations of appendicitis reports that while dysuria as a symptom of appendicitis can occur occasionally, symptoms of bladder flow obstruction do not. ${ }^{3}$ A literature review indicates that this is only the second case of this nature published to date.

This case illustrates the importance of the recognition of unusual manifestations of common emergencies.

This patient had a history and examination that was clinically consistent with prostatitis, but without any of the usual risk factors for such a condition (urinary tract infection, recent instrumentation, epididymitis or anatomical abnormality).

With his strong family history of juvenile cancer, the possibility of the mass being malignant could not be ruled out for which a haemicolectomy was done.

However, appendicitis is the most common abdominal emergency in the UK, responsible for $>40000$ admissions in England each year. ${ }^{4}$ Appendicitis should therefore always be considered for abdominal and pelvic presentations, especially in adolescent patients with no medical history, and especially in those who are not responding well to treatment of potentially incorrect primary diagnoses.

Contributors All coauthors have made substantial contribution to this case report. NS: the admitting doctor on the team and wrote the majority of the case report. TS: helped with planning, writing of the case and proofreading. AC: responsible for the care of the patient and made significant contribution in editing the paper. AQ: responsible consultant for the care of the patient; was heavily involved with the writing of the case report and always contactable to discuss any issues.

\section{Learning points}

- Appendicitis can present with a wide range of presenting symptoms.

- This includes the rare presentation of dysuria and prostatic obstruction.

- The absence of abdominal pain or tenderness does not exclude a pelvic appendicitis.

- Prostatitis is unusual in young men with no risk factors (recent instrumentation, previous urinary tract infection, epididymitis or anatomical abnormality).

- Acute appendicitis should be included in the differential diagnosis of acute urological presentations.

Competing interests None declared.

Patient consent Obtained.

Provenance and peer review Not commissioned; externally peer reviewed.

(c) BMJ Publishing Group Ltd (unless otherwise stated in the text of the article) 2017. All rights reserved. No commercial use is permitted unless otherwise expressly granted.

\section{REFERENCES}

1 Jones WG, Barie PS. Urological manifestations of acute appendicitis. J Urol 1988;139:1325-8

2 Guidry SP, Poole GV. The anatomy of appendicitis. Am Surg 1994;60:68-71.

3 Tundidor Bermúdez AM, Amado Diéguez JA. Montes De Oca Mastrapa jl.urological manifestations of acute appendicitis. Arch Esp Urol 2005:58:207-12.

4 Humes DJ, Simpson J. Acute appendicitis. BMJ 2006;333:530-4.

Copyright 2017 BMJ Publishing Group. All rights reserved. For permission to reuse any of this content visit

http://group.bmj.com/group/rights-licensing/permissions.

BMJ Case Report Fellows may re-use this article for personal use and teaching without any further permission.

Become a Fellow of BMJ Case Reports today and you can:

- Submit as many cases as you like

- Enjoy fast sympathetic peer review and rapid publication of accepted articles

- Access all the published articles

- Re-use any of the published material for personal use and teaching without further permission

For information on Institutional Fellowships contact consortiasales@bmjgroup.com

Visit casereports.bmj.com for more articles like this and to become a Fellow 